\title{
Clinical profile and outcome of multisystem inflammatory syndrome in children in a tertiary care centre of North Kerala: a prospective study
}

\author{
Naveena Sajeevan*, Mohammed Manakkatt T, P., \\ Kavitha Pavithran, Urmila Muraleekrishnan K. V.
}

Department of Pediatrics, Government Medical College Kannur, Kerala, India

Received: 17 October 2021

Revised: 09 November 2021

Accepted: 12 November 2021

\section{*Correspondence:}

Dr. Naveena Sajeevan,

E-mail: drnaveena1991@gmail.com

Copyright: ( ) the author(s), publisher and licensee Medip Academy. This is an open-access article distributed under the terms of the Creative Commons Attribution Non-Commercial License, which permits unrestricted non-commercial use, distribution, and reproduction in any medium, provided the original work is properly cited.

\begin{abstract}
Multisystem inflammatory syndrome in children (MIS-C) is a newly emerged disease following the outbreak of COVID-19. The nomenclature is given by WHO. Similar condition is named as paediatric inflammatory multisystem syndrome-temporally associated with SARS-CoV2 virus (PIMS-TS), by RCPCH. To study the clinical profile and outcome of MIS-C in 2 months to 18 years old. The 25 children, admitted in PICU and pediatrics ward were included in the study. The $79 \%$ required PICU admission and two required mechanical ventilation. One child expired. Children presented with conjunctival congestion (53\%), diarrhoea (47\%), cervical lymphadenopathy (37\%), shock $(31.5 \%)$, vomiting $(36.8 \%)$, rashes $(36.8 \%)$, mucosal erythema $(36.8 \%)$, cough $(10.5 \%)$ and headache $(10.5 \%)$. Inflammatory markers were elevated in all the children. On initial echocardiography, 4 children $(21 \%)$ had LV dysfunction with LVEF $<50 \%$. Six children $(31.5 \%)$ were treated with IVIG and IV methylprednisolone, changed to oral prednisolone after 3 days and continued for 2 weeks. Three children (18\%) were treated with IVIG and oral prednisolone. Two children $(12 \%)$ were treated with IVIG alone. Eight children $(47 \%)$ were treated with methylprednisolone alone. The median duration of hospitalisation was 5 days. 18 children (94.7\%) were discharged to home within one week of admission. One 8 months old baby presented with shock, succumbed to death in spite of giving IV methyl prednisolone and IVIG. In our study we observed that early diagnosis and treatment with IVIG or steroids offers good outcome for the condition. Of the 19 children studied, 17 children were discharged within one week.
\end{abstract}

Keywords: Multisystem inflammatory syndrome, Intravenous immunoglobulin, Cytokine storm

\section{INTRODUCTION}

Multisystem inflammatory syndrome in children (MIS-C) is a newly emerged disease following the outbreak of COVID-19, reported from across the world. The nomenclature is given by WHO. ${ }^{1}$ Similar condition is named as paediatric inflammatory multisystem syndrome-temporally associated with SARS-CoV virus (PIMS-TS), by RCPCH. ${ }^{2}$ During the initial phase of the pandemic children less than 18 years have been reported to be affected very less and the manifestations were usually milder illness. This new hyper inflammatory syndrome shares features of Kawasaki disease, toxic shock syndrome, macrophage activation syndrome etc. Treatment with various drugs including intravenous immunoglobulin (IVIG), methyl prednisolone and biologicals like infliximab and tocilizumab have been tried with varying results.,

\section{Relevance of the study}

Since this is a newly emerging condition, awareness about the clinical manifestation is important for early 
recognition and instituting prompt treatment which may improve the outcome.

This study is to describe the clinical features and treatment of MIS-C and to analyse the outcome.

\section{CASE SERIES}

We included children in the age group of 2 months-18 years admitted in pediatric ICU and ward with clinical and laboratory features satisfying WHO criteria for MISC. Children with autoimmune disease and those who were not willing to participate in the study were excluded. A detailed history and examination were done, observing complete COVID-19 protocol. Investigations like CBC, ESR, CRP, Urine R/E, LFT, RFT, LDH, serum ferritin, trop I, BNP (Brain natriuretic peptide), d-dimer, $\mathrm{x}$-ray chest, USG abdomen, ECG and echo were done. COVID-19 confirmation was done by using either rapid antigen test (RAT), real time reverse transcriptase polymerase chain reaction (RT-PCR). In patients whose RTPCR /RAT was negative, serological assay was done. Data entered in a predesigned proforma and analysed. Details of treatment given were also analysed. Data collected were entered in Microsoft excel spreadsheet and analysed. Demographic and clinical features were described using frequencies/percentages. Measures of central trends and dispersion were used for continuous variables. Complete investigations and treatment of confirmed COVID-19 patients were given free of cost as per the government protocol. The cost of investigations not included in government protocol (COVID immunoglobulin assay) was borne by the investigator.

The 25 children, admitted in pediatrics ICU and pediatrics ward were included in the study. The median age of these patients was 5 years ( 8 months to 14 years) and $60 \%$ of them were boys $(n=15) .52 \%$ of children were less than 5 years old. All the children had high grade fever for $>3$ days. Children presented with conjunctival congestion $(60 \%)$, diarrhoea (52\%), cervical lymphadenopathy $(36 \%)$, shock $(36 \%)$, vomiting $(40 \%)$, rashes $(44 \%)$, mucosal erythema $(24 \%)$, cough $(8 \%)$ and headache $(24 \%)$. One child presented with seizures and complete heart block.

Inflammatory markers were elevated in all the children. CRP $>50 \mathrm{mg} / \mathrm{dl}$ in $88 \%$, ESR $>40 \mathrm{~mm} / \mathrm{hr}$ in $71 \%$ of children. S. Ferritin was $>500 \mathrm{ng} / \mathrm{ml}$ in $53 \%$. Thrombocytopenia was present in 15 children $(60 \%)$ and lymphopenia in 16 children $(64 \%)$. D dimer was done in 18 children, all of them were elevated. S. LDH was elevated in 14 children (56\%). Trop I/BNP was positive in $12(48 \%)$ children. On initial echocardiography, 5 children $(20 \%)$ had LV dysfunction with LVEF $<50 \%$, coronary dilatation was present in one child (4\%). ECG was normal in all the children except one who presented with complete heart block. Chest x-ray was normal in $84 \%$. Mild pleural effusion was noticed in 2 children. One child had pulmonary oedema. USG abdomen showed mesenteric lymphadenitis in two children and gallbladder wall thickness in one child.

COVID antigen was positive in 2 children, RTPCR was positive in 2. COVID antibody was positive in 15 children. 8 children had high risk contact with positive patients.

The 11 children (44\%) were treated with IVIG and IV methylprednisolone, changed to oral prednisolone after 3 days and continued for 2 weeks. Three children (12\%) were treated with IVIG and oral prednisolone. Two children $(8 \%)$ were treated with IVIG alone. Nine children $(36 \%)$ were treated with methylprednisolone alone. Seven children (28\%) required ionotropes. Aspirin was given for all the children. The $84 \%(n=21)$ required ICU admission. The median duration of hospitalisation was 6 days. Repeat echo done at 2 weeks were normal for all the 24 children. One 11-year-old girl was presented with seizures and complete heart block, required mechanical ventilation and temporary pacemaker insertion for 1 week, discharged after 12 days without any sequel. One 8 months old baby presented with shock, succumbed to death in-spite of giving IV methyl prednisolone and IVIG.

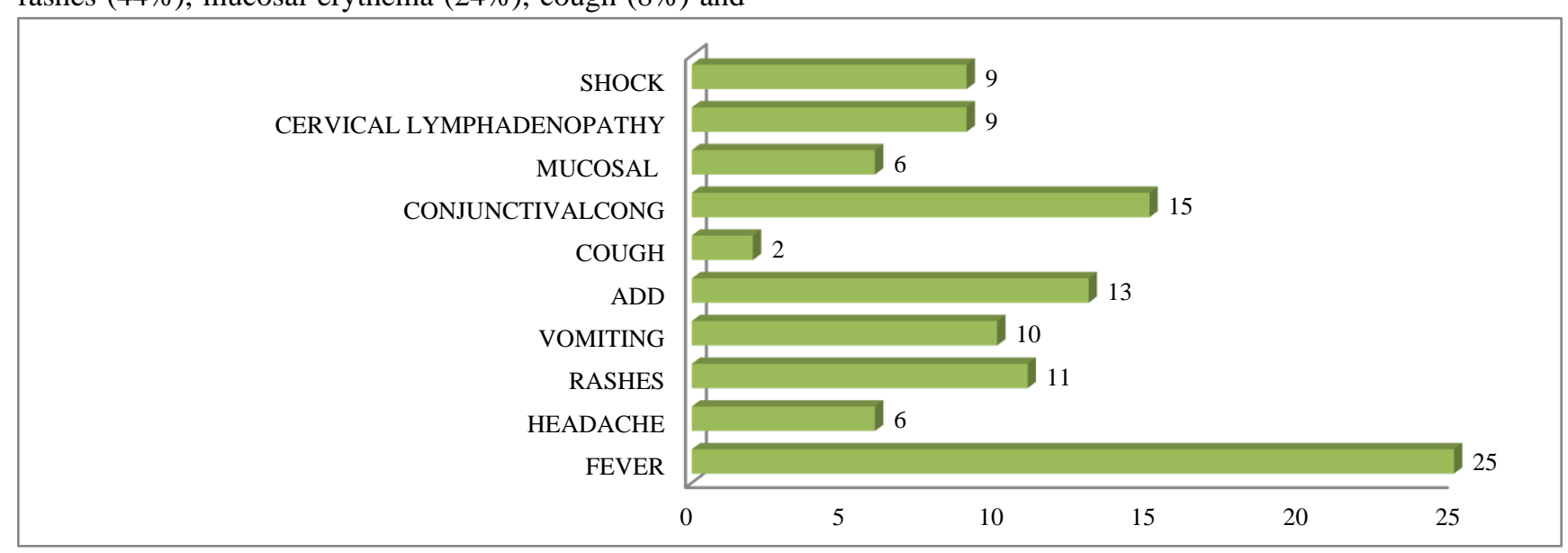

Figure 1: Clinical features of MIS-C. 


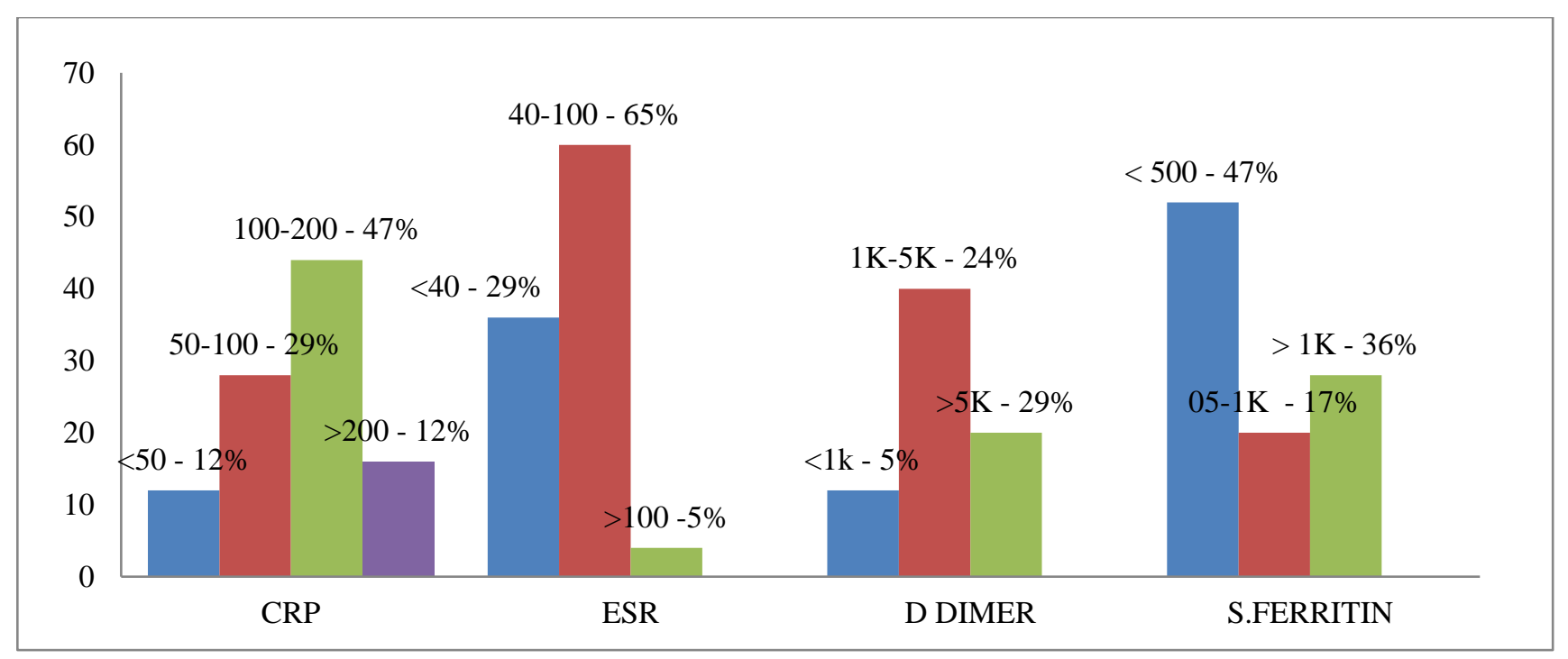

Figure 2: Change inflammatory markers in MISC.

\section{DISCUSSION}

Pediatric inflammatory multisystem syndrome temporarily associated with SARS COV2/MIS-C is an emerging disease in post COVID patients. The first report on the disease was from UK. ${ }^{5}$ In April 2020 they noted a cluster of 8 children with features similar to atypical Kawasaki disease or toxic shock syndrome. All tested negative for SARS-CoV-2 antigen. Inflammatory markers including C-reactive protein, procalcitonin, ferritin, and D-dimers were elevated. No pathological organism was identified in 7 of them. 4 children had an epidemiologic link to a COVID-19 case.

We studied 25 patients with MIS-C, of whom $84 \%$ required ICU admission and 2 children required mechanical ventilation. Children presented herein had relatively early consultation in our hospital, except for 1 who presented with 8 days of fever. In our study median age of presentation was 5 years, relatively younger age group compared to studies conducted in other centres. ${ }^{6,4}$ Most common presentation was fever with non-purulent conjunctivitis and gastrointestinal symptoms similar to studies conducted by Elizabeth et al and Riphagen et al. ${ }^{7,5}$

In this series cardiac involvement was present in $48 \%$ of patients, of which $36 \%$ presented with shock. Coronary dilatation was present only in one child. A 11 years old girl presented with complete heart block. She required temporary pacemaker insertion for 6 days and was on mechanical ventilator for 6 days. Cardiovascular complications are common in MIS-C, but cardiac arrhythmias are rare. In a study by Dionne et al firstdegree atrioventricular block (AVB) was seen in $5(20 \%)$ patients and second- or third-degree AVB in 4 patients. No patient required intervention for AVB in their cohort. QTc prolongation was seen in 7 patients $(28 \%)$, and nonspecific ST segment changes were seen in 14 patients (56\%). Ectopic atrial tachycardia was observed in 1 patient, and none developed ventricular arrhythmias. ${ }^{8}$ Domico et al from California reported a case of MIS-C with High-grade heart block requiring transvenous pacing. ${ }^{9}$ ECG monitoring in children with MIS-C is of at most importance as they are at risk for atrioventricular conduction disease.

Most children received IVIG and steroids. The 11 children (44\%) were treated with IVIG and IV methylprednisolone 3 children (12\%) were treated with IVIG and oral prednisolone. Two children (8\%) were treated with IVIG alone. Nine children $(36 \%)$ were treated with methylprednisolone alone. Rapid response was observed in $96 \%$ of the patients. Similar response was observed in studies conducted in other centres. ${ }^{10,11}$ Outcome in our series was good, with one death. Median duration of hospital stay was 6 days. The 84\% required PICU admission. Only two required mechanical ventilation. Comparable to studies by Kaushik et al and Riphagen et al. ${ }^{3,5}$ No patients needed biological agents in our cohort. Biologicals were used in the treatment of MISC in US and UK with successful outcome. The 14 (8\%) received interleukin-6 inhibitors (tocilizumab or siltuximab), and 24 (13\%) received an interleukin-1 inhibitor (anakinra) in a US study. ${ }^{12}$ The $36 \%$ of patients received Tocilizumab in New York study. ${ }^{3}$

In our cohort, one child presented with high grade fever and shock died on sixth day of admission. He had relatively late consultation in our hospital, presented with history of high-grade fever for 1 week. Child received IVIG and methylprednisolone and was on mechanical ventilator for 3 days. This reinforces the need for early suspicion and treatment of the condition.

One of the initial challenges in diagnosing MIS-C was its overlapping clinical features with other conditions like Kawasaki disease, toxic shock syndrome etc. Kawasaki disease is a vasculitis that typically presents with high fever and acute mucocutaneous inflammation in children 
$<5$ years of age. ${ }^{13}$ Toxic shock syndrome is a potentially lethal disease derived from the release of bacterial toxins. ${ }^{14}$ In our study $60 \%$ of children had clinical features of incomplete Kawasaki disease. The overlapping features between these syndromes suggests that they may share similar pathophysiology. ${ }^{15}$ An article published by Whittaker et al describes the overlapping features of MIS-C and other pediatric inflammatory syndromes. ${ }^{16}$

It was observed that children could develop MIS-C despite an asymptomatic course of coronavirus 2019 disease. ${ }^{17}$ In our study most of the children had asymptomatic or mildly symptomatic corona virus 2019 disease before the diagnosis of MIS-C.

Studies conducted in other centres suggests that peak incidence of MIS-C happened at 3-4 weeks after the peak of COVID-19 disease. ${ }^{12,18}$ In our study 2 children were positive for corona virus disease antigen test, suggests that children had active corona virus disease along with MIS-C.

MISC is an emerging disease with unknown sequelae. ${ }^{19}$ Its coronary and neurological outcomes needs to be monitored on a long term basis. Our study describes primary analysis of an ongoing hospital study. Small sample size and limited period of follow up are the major drawbacks of the study. A multicentre study with larger sample size can describe the clinical features and outcome with more accuracy.

\section{CONCLUSION}

In conclusion, MIS-C is an inflammatory condition that progress rapidly over days. Children often presents in shock and cardiac failure. Most of the children require emergency medical attention and ICU care in a tertiary hospital. In our study we observed that early diagnosis and treatment with IVIG or steroids offers good outcome for the condition. Follow up echocardiography and other investigations were normal for all of them.

\section{ACKNOWLEDGEMENTS}

Author would like to thanks department of paediatrics, government medical college, Kannur and all the children and their parents for participating in the study.

Funding: No funding sources

Conflict of interest: None declared

Ethical approval: Not required

\section{REFERENCES}

1. World Health Organization. Multisystem inflammatory syndrome in children and adolescents temporally related to COVID-19: Scientific Brief 2020. WHO. 2020;10:1-9. Available at: https://www.who.int/news- room/commentaries/detail/multisysteminflammatory-syndrome-in-children-andadolescents-with-covid-

19\%0Ahttp://www.who.int/newsroom/commentaries/detail/multisysteminflammatory-syndrome-in-children-andadolescents-with-covid-19. Accessed on 15 May 2021.

2. Royal College of Paediatrics and Child Health. Paediatric multisystem inflammatory syndrome temporally associated with COVID-19 (PIMS)guidance for clinicians. Royal College of Paediatrics and Child Health. 2020. Available at: https://www.rcpch.ac.uk/resources/guidancepaediatric-multisystem-inflammatory-syndrometemporally-associated-covid-19. 15 May 2021.

3. Kaushik S, Aydin SI, Derespina KR, Bansal PB, Kowalsky S, Trachtman R et al. Multisystem Inflammatory Syndrome in Children (MIS-C) Associated with SARS-CoV-2 Infection: A Multiinstitutional Study from New York City. J pediatr (Rio J). 2020;

4. Jain S, Sen S, Lakshmivenkateshiah S, Bobhate P, Venkatesh S, Udani $S$ et al. Multisystem Inflammatory Syndrome in Children With COVID19 in Mumbai, India. Indian Pediatr. 2020;57(11):1015-9.

5. Riphagen S, Gomez $\mathrm{X}$, Gonzalez-Martinez $\mathrm{C}$, Wilkinson N, Theocharis P. Hyperinflammatory shock in children during COVID-19 pandemic. Lancet. 2020;395:1607-8.

6. Ramcharan T, Nolan O, Lai CY, Prabhu N, Krishnamurthy R, Richter AG et al. Paediatric Inflammatory Multisystem Syndrome: Temporally Associated with SARS-CoV-2 (PIMS-TS): Cardiac Features, Management and Short-Term Outcomes at a UK Tertiary Paediatric Hospital. Pediatr Cardiol. 2020;41(7):1391-401.

7. Dufort EM, Koumans EH, Chow EJ, Rosenthal EM, Muse A, Rowlands $\mathrm{J}$ et al. Multisystem Inflammatory Syndrome in Children in New York State. N Engl J Med. 2020;383(4):347-58.

8. Dionne A, Mah DY, Son MBF, Lee PY, Henderson L, Baker AL et al. Atrioventricular Block in Children with Multisystem Inflammatory Syndrome. Pediatrics. 2020;146:5.

9. Domico M, McCanta AC, Hunt JL, Ashouri N, Nugent D, Kelly RB. High-grade heart block requiring transvenous pacing associated with multisystem inflammatory syndrome in children during the COVID-19 pandemic. Hear Case Reports. 2020;6(11):811-4.

10. Belhadjer Z, Méot M, Bajolle F, Khraiche D, Legendre A, Abakka $S$ et al. Acute Heart Failure in Multisystem Inflammatory Syndrome in Children in the Context of Global SARS-CoV-2 Pandemic. Circulation. 2020;142(5):429-36.

11. Torres JP, Izquierdo G, Acuña M, Pavez D, Reyes F, Fritis A et al. Multisystem inflammatory syndrome in children (MIS-C): Report of the clinical and 
epidemiological characteristics of cases in Santiago de Chile during the SARS-CoV-2 pandemic. Int $\mathbf{J}$ Infect Dis. 2020;100:75-81.

12. Feldstein LR, Rose EB, Horwitz SM, Collins JP, Newhams MM, Son MBF et al. Multisystem Inflammatory Syndrome in U.S. Children and Adolescents. N Engl J Med. 2020;383(4):334-46.

13. Correction to: Diagnosis, Treatment, and Long-Term Management of Kawasaki Disease: A Scientific Statement for Health Professionals from the American Heart Association. Circulation. 2019;140:E181-4.

14. Gottlieb M, Long B, Koyfman A. The Evaluation and Management of Toxic Shock Syndrome in the Emergency Department: A Review of the Literature. J Emerg Med. 2018;54(6):807-14.

15. Ahmed M, Advani S, Moreira A, Zoretic S, Martinez $\mathrm{J}$, Chorath $\mathrm{K}$ et al. Multisystem inflammatory syndrome in children: A systematic review. EClin Med. 2020;26.

16. Whittaker E, Bamford A, Kenny J, Kaforou M, Jones $\mathrm{CE}$, Shah $\mathrm{P}$ et al. Clinical Characteristics of 58 Children with a Pediatric Inflammatory Multisystem
Syndrome Temporally Associated with SARS-CoV2. J Am Med Assoc. 2020;324(3):259-69.

17. Chiotos K, Bassiri H, Behrens EM, Blatz AM, Chang J, Diorio C et al. Multisystem inflammatory syndrome in children during the coronavirus 2019 pandemic: A case series. J Pediatric Infect Dis Soc. 2020;9(3):393-8.

18. Godfred-Cato S, Bryant B, Leung J, Oster ME, Conklin L, Abrams J et al. COVID-19-Associated Multisystem Inflammatory Syndrome in ChildrenUnited States, March-July 2020. MMWR Morb Mortal Wkly Rep. 2020;69(32):1074-80.

19. Verdoni L, Mazza A, Gervasoni A, Martelli L, Ruggeri M, Ciuffreda M et al. An outbreak of severe Kawasaki-like disease at the Italian epicentre of the SARS-CoV-2 epidemic: an observational cohort study. Lancet. 2020;395(10239):1771-8.

Cite this article as: Naveena S, Mohammed MTP, Pavithran K, Urmila KV. Clinical profile and outcome of multisystem inflammatory syndrome in children in a tertiary care centre of North Kerala: a prospective study. Int J Contemp Pediatr 2021;8:1972-6. 